\title{
Effect of an ambulatory diagnostic and treatment programme in patients with sleep apnoea
}

\author{
A.L. Andreu*, E. Chiner*, J.N. Sancho-Chust*, E. Pastor*, M. Llombart*, \\ E. Gomez-Merino*, C. Senent* and F. Barbé ${ }^{\#}$
}

ABSTRACT: The aim of this study to evaluate the efficacy of a home-based programme on clinical response, continuous positive airway pressure (CPAP) compliance and cost in a population of high pre-test probability of suffering obstructive sleep apnoea syndrome (OSAS).

Patients were randomised into the following three groups. Group A: home respiratory polygraphy (RP) and home follow-up; group B: hospital polysomnography and hospital followup; and group C: home RP and hospital follow-up. Evaluation during 6 months included Epworth Sleepiness Scale (ESS), Functional Outcomes Sleep Questionnaire (FOSQ), and daily activity and symptom questionnaires. Compliance was assessed by memory cards (group A) and using an hourly counter (groups B and C).

66 patients were included (22 per branch), 83\% were males, aged mean \pm SD $52 \pm 10$ yrs, body mass index $34 \pm 7 \mathrm{~kg} \cdot \mathrm{m}^{-2}$, apnoea/hypopnoea index $43 \pm 20 \mathrm{~h}^{-1}$, CPAP pressure $8 \pm 2 \mathrm{cmH}_{2} \mathrm{O}$, with no between-group differences. Clinical response showed an ESS of mean \pm SD $15 \pm 3$ to $6 \pm 4$, a FOSQ of $16 \pm 3$ to $18 \pm 2$, symptoms of $43 \pm 7$ to $25 \pm 7$, and activity of $37 \pm 11$ to $25 \pm 8$. At the end of the study, compliance was: group A 73\%, group B $68 \%$ and group C $57 \%$. The cost per patient was: group $A € 590 \pm 43$, group $B € 894 \pm 11$ and group $C € 644 \pm 93(p<0.001)$.

In conclusion, patients with a high initial probability of having OSAS can be diagnosed and treated in a home setting, with a high level of CPAP compliance and lower cost than using either a hospital-based approach or home RP/hospital follow-up.

KEYWORDS: Ambulatory programme, continuous positive airway pressure, home-based programme, sleep apnoea

bstructive sleep apnoea syndrome (OSAS) is a highly prevalent disease $[1,2]$ that has been shown to be associated with a reduction in quality of life [3], the onset or worsening of hypertension [4, 5], cardiovascular diseases [6] and stroke [7], increased traffic and workplace accidents $[8,9]$, and mortality [10].

The gold standard for diagnosis is polysomnography (PSG) [11], but it is expensive, not available in all hospitals and frequently has long waiting lists [12]. Respiratory polygraphy (RP) is a cheaper and more accessible test and correlates well with PSG [13-15]. Home-based diagnostic strategies based on simple automated evaluation and treatment systems have also been proposed [16].

Treatment with continuous positive airway pressure (CPAP) has been shown to improve symptoms and quality of life, decrease traffic accidents and may have a positive effect on cardiovascular morbidity $[5,17,18]$. The effectiveness of this treatment is directly related to compliance $[19,20]$. Strict follow-up is required for improvement, principally in the first few months [19]. Various strategies have been assayed to improve compliance, such as reinforcement by telephone, educational sessions, etc. [21-25].

The number of patients referred with suspected OSAS has increased considerably in recent years [26], overloading diagnostic and follow-up resources. To guarantee effective, efficient and integral care and management of patients, alternatives to traditional methods need to be considered [21, 26].

The aim of this study was to ascertain, in a sample of moderate and severe OSAS patients, whether
AFFILIATIONS

*Pulmonology Section, University Hospital of Sant Joan d'Alacant, Alicante, and

${ }^{\text {\#} R e s p i r a t o r y ~ D e p t, ~ I R B ~ L l e i d a ~}$ (Lleida), CIBERES, ISCIII, Madrid, Spain.

CORRESPONDENCE

E. Chiner

Secció de Pneumologia

Hospital Universitari Sant Joan

d'Alacant

Ctra. Alacant-València s/n. CP 03550

Sant Joan d'Alacant

Spain

E-mail: chiner_eus@gva.es

Received:

Jan 242011

Accepted after revision:

June 162011

First published online:

June 302011 
an ambulatory assessment programme would be as effective for compliance and clinical response as a regular hospital programme. Thus, we investigated whether this programme was a realistic alternative to conventional hospital diagnosis and follow-up.

\section{MATERIAL AND METHODS \\ Study subjects}

All patients referred with a high level of clinical suspicion of OSAS, based on an Epworth Sleepiness Scale (ESS) score $\geqslant 12$ and a Sleep Apnoea Clinical Score (SACS) $\geqslant 15$, were included [27]. Patients were recruited during a 6-month period $(\sim 12$ patients were referred each week to our sleep unit at the Pulmonology Section of the University Hospital of Sant Joan d'Alacant). During this period, 333 subjects were referred to our sleep unit, 250 of whom had a clinical suspicion of OSAS. After diagnostic procedures, $75 \%$ of these were diagnosed as having OSAS, while $25 \%$ were diagnosed with no OSAS. Of the OSAS patients, 30\% were diagnosed with severe OSAS. The $30 \%$ of referred subjects with a clinical suspicion of OSAS also had a high pre-test probability of OSAS, based on the study's inclusion criteria. Patients with impaired lung function (chronic obstructive pulmonary disease, obesity-hypoventilation and restrictive disorders), associated pathologies (psychiatric disorders, neoplasms, restless leg syndrome and other dyssomnias or parasomnias), and patients previously treated with CPAP were all excluded.

\section{Methods}

PSG (Somnostar Alpha 4100®; SensorMedics, San Anselmo, CA, USA) was carried out in the hospital setting under the supervision of a nurse, according to the guidelines by the Spanish Society of Pulmonology and Thoracic Surgery (SEPAR) [28].

RP (Stardust Polygraph ${ }_{\circledR}$; Phillips Respironics Inc., Murraysville, PA, USA) was carried out at home without direct vigilance, using a validated system [29]. An apnoea/hypopnoea index (AHI) $>15$ was necessary to diagnose OSAS [30]. If the register was invalid, a second RP was carried out.

Specific questionnaires validated in Spanish were used to evaluate ESS [31, 32], quality of life, Functional Outcomes Sleep Questionnaire (FOSQ) [32,33], activity and symptoms [18], and the presence of snoring while under CPAP treatment.

\section{Study design}

This work was a year-long, randomised, prospective study with three parallel arms. Patients were randomised into three groups, A, B or C (fig. 1).

The demographic characteristics and questionnaire scores at baseline are shown in tables 1 and 2, with no differences between groups.

The randomisation assignments were computer generated using a block permutation method to select one of the three diagnostic and follow-up alternatives. Randomisation was performed by the staff of our hospital's research unit (Pulmonology Section of the University Hospital of Sant Joan d'Alacant), who had no direct participation in the study. To ensure adequate blinding, opaque and sealed envelopes were used. After a manual reading of the sleep study, patients were evaluated in a second ambulatory visit, given their CPAP treatment assignment and informed about the treatment, adverse effects and short- and long-term benefits. All

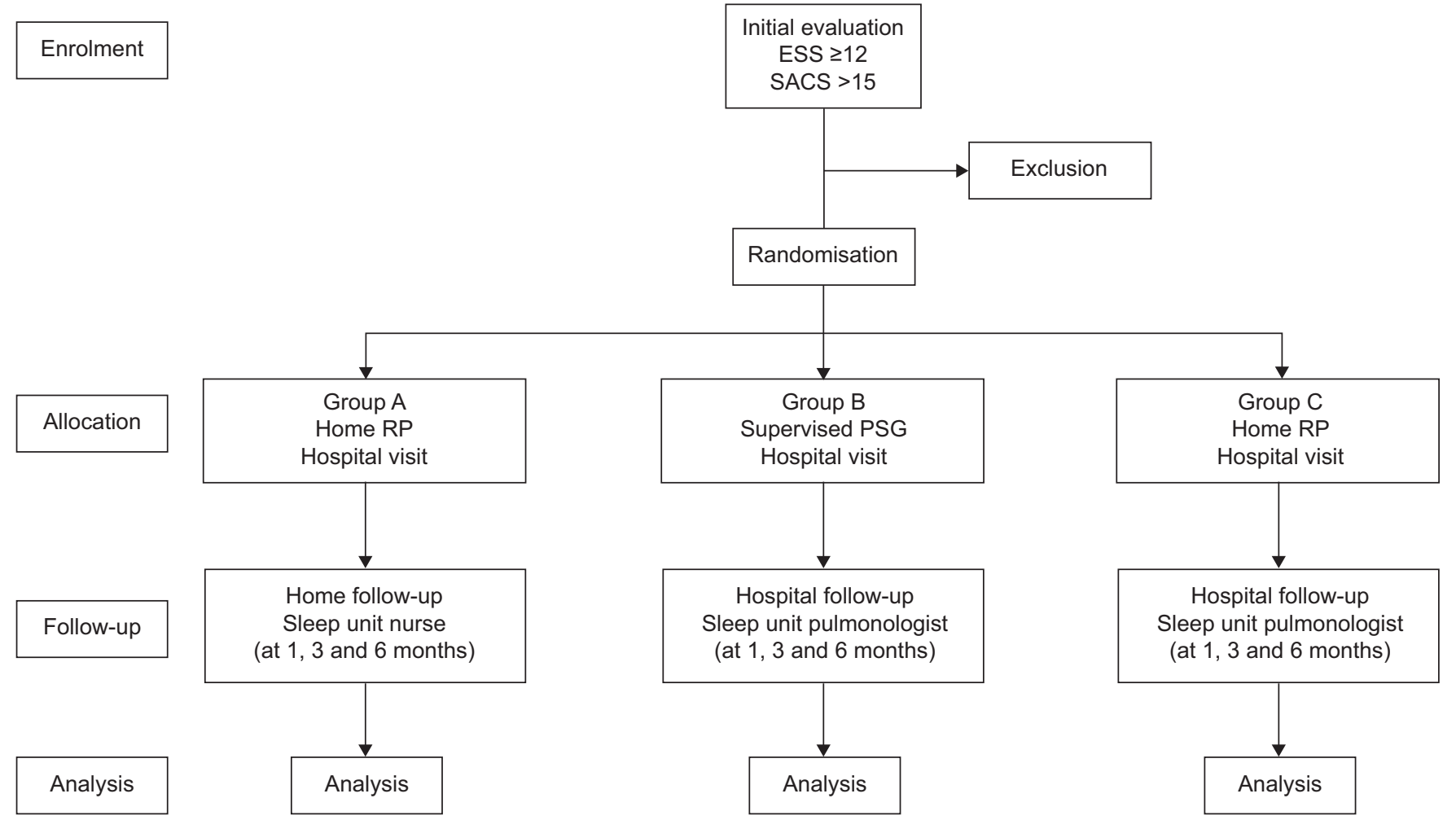

FIGURE 1. Study protocol. ESS: Epworth Sleepiness Score; SACS: Sleep Apnoea Clinical Score; RP: respiratory polygraphy; PSG: polysomnography. 


\begin{tabular}{lccccc} 
TABLE 1 & $\begin{array}{c}\text { Demographic characteristics of patients } \\
\text { All } \\
\text { patients }\end{array}$ & Group A & Group B & Group C & p-value \\
& & & & & \\
\hline Subjects $\mathbf{n}$ & 65 & 22 & 22 & 21 & \\
Age yrs & $52 \pm 10$ & $52 \pm 11$ & $53 \pm 9$ & $51 \pm 10$ & NS \\
Male & $54(83)$ & $18(82)$ & $21(96)$ & $15(71)$ & NS \\
Female & $11(17)$ & $4(18)$ & $1(4)$ & $6(29)$ & NS \\
BMI kg $\cdot \mathbf{m}^{-2}$ & $34 \pm 7$ & $32 \pm 5$ & $34 \pm 7$ & $36 \pm 7$ & NS \\
Neck circumference & $45.5 \pm 3.5$ & $45.4 \pm 3.7$ & $45.3 \pm 3.3$ & $45.9 \pm 3.2$ & NS \\
$\quad$ cm & & & & & \\
Hypertension & $32(49)$ & $11(50)$ & $12(55)$ & $9(43)$ & NS \\
Habitual snoring & 100 & 100 & 100 & 100 & NS \\
SACS & $40 \pm 26$ & $41 \pm 29$ & $39 \pm 25$ & $41 \pm 25$ & NS \\
\hline
\end{tabular}

Data are presented as mean $\pm \mathrm{SD}, \mathrm{n}(\%)$ or \%, unless otherwise stated. BMI: body mass index; SACS: Sleep Apnoea Clinical Score; Ns: nonsignificant.

patients fulfilled the CPAP treatment criteria [28]. CPAP was calculated mathematically using the following equation: $-5.12+$ $(0.13 \times$ body mass index $(\mathrm{BMI}))+(0.16 \times$ neck circumference $)$ $+(0.04 \times \mathrm{AHI})[34,35]$, and pressure was not changed during follow-up. A CPAP humidifier was not used in any patients.

Group A was followed at home and patients were treated using a CPAP device (REMstar $®$ Pro; Philips Respironics Inc.) with a memory card (to store the number of hours of use, the number of days of use per week and the time of use). During each visit, the nurse collected the memory card for later analysis and delivery to the supervising physician. The nurse also administered the questionnaires and interviewed patients about side-effects. If poor compliance was reported by the patient $\left(<4 \mathrm{~h} \cdot\right.$ night $^{-1}$ for $70 \%$ of nights) or if the patient had a negative attitude to CPAP treatment, the nurse assessed the need for specialist reinforcement, either via a telephone call or in a scheduled visit, to improve compliance or resolve adverse effects (see online supplementary material).

In groups B and C (hospital follow-up), after the diagnosis, the working principles of CPAP were explained to the patients and a first adaptation was performed with the patient awake. Followup was done by physicians routinely in the sleep unit. The effective compliance was calculated using an hourly CPAP (REMstar ${ }_{\circledast}$ M, Philips Respironics Inc.) counter, and dividing the total hours registered on the counter by the number of days of treatment.

All patients (groups A, B and C) were contacted at least once by the physician supervising the programme via telephone during the first month.

Patients were classified as compliant if they completed at least $4 \mathrm{~h}$ of treatment on $70 \%$ of the days of the week in the three groups [36].

\section{Cost evaluation}

The estimated costs of each strategy were calculated and compared between groups. The estimated costs of hospital visits, telephone calls and the PSG were obtained from the Financial Department of the San Juan de Alicante University
Hospital, Alicante, Spain, and the previously estimated data for our unit [37]. The costs of home visits, the RP and the daily cost of CPAP were obtained directly from the company that provided home respiratory therapy [38].

\section{Analysis}

The main outcome was to evaluate the compliance between groups at 6 months of follow-up. The secondary outcomes were daytime sleepiness (ESS), quality of life as measured by the FOSQ, symptoms, and cost per patient and group.

The study was planned as a noninferiority trial, in order to demonstrate that home-based follow-up produces similar compliance and outcomes to hospital-based follow-up, with the latter as the current standard strategy (active control). To calculate the sample size, a 5\% margin in hours of CPAP use was considered to be the noninferiority margin in the patients considered as compliant (with the following expected criteria: a loss of $5 \%, \alpha$ error of 0.05 and a power of 0.9 , taking into account that $30 \%$ of patients in each group could be poorly CPAP compliant or definitively abandon CPAP at some point during follow-up).

We estimated that a sample size of 75 consecutive patients who fulfil the inclusion criteria, 25 in each group, would be necessary to demonstrate equivalent clinical efficacy with respect to compliance with the three methodologies.

To compare the number of hours of CPAP use between the three groups, ANOVA or the Kruskal-Wallis test were used when appropriate, with a subsequent pairwise comparison of means. Numerical data were expressed as mean \pm SD. The effect or dependent variable was the number of hours on the CPAP counter. The same tests were used to compare the following numerical variables: BMI, neck circumference, ESS and FOSQ score, costs in euros and symptom questionnaires. One-way ANOVA and the Newman-Keuls test for pairwise comparisons were used to assess FOSQ changes over time in each of the groups. The Chi-squared or Fisher's exact tests were used for categorical variables. All analyses were done by intention to treat. A p-value $<0.05$ was considered statistically significant.

\section{Ethical issues}

The study was approved by the Ethics and Clinical Trials Committee of the San Juan de Alicante University Hospital, Alicante, Spain, and informed consent was obtained from all included patients. This study is registered at the clinical trials registry (www.clinicaltrials.gov; number NCT01001858).

\section{RESULTS}

Figure 2 shows the study flow chart. 66 patients were eligible for randomisation. A patient in group $\mathrm{C}$ was excluded for presenting an AHI $<8 \mathrm{~h}^{-1}$ and refusing to undergo a PSG; one from group A died due to causes unrelated to OSAS, five were lost to follow-up (one from group $\mathrm{A}$, one from $\mathrm{B}$ and three from C). One patient from group A attended the final visit, but had abandoned treatment and was considered noncompliant (fig. 2). The remaining 58 completed the programme. The baseline characteristics of patients who were not enrolled were similar to those who were randomised (data not shown).

The AHI, desaturation index and CPAP pressure values were not different between groups (table 3 ). The number of patients 
TABLE 2 Baseline and follow-up scoring of questionnaires

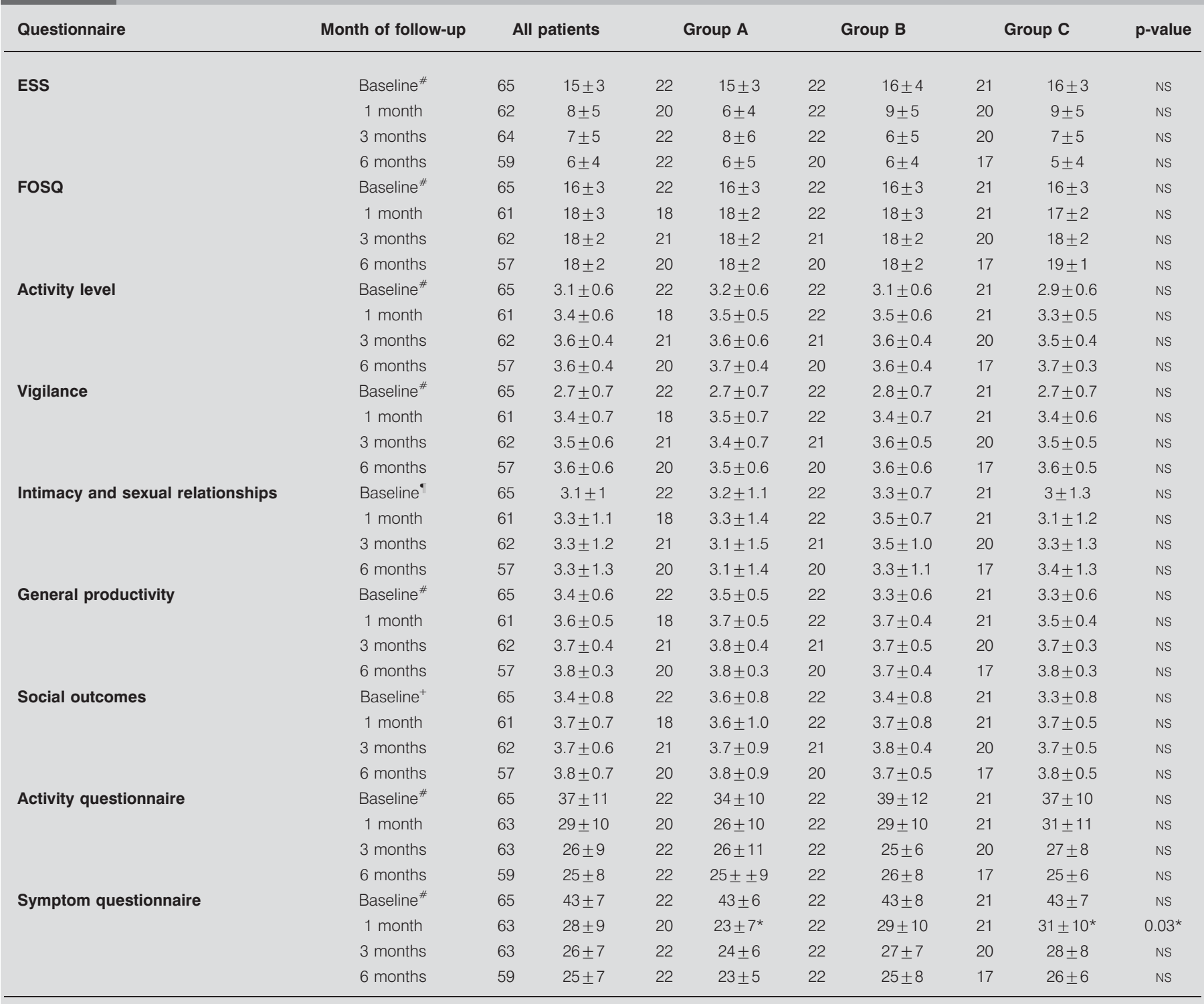

Data are precented as $n$ or mean \pm SD, unless otherwise stated. ESS: Epworth Sleepiness Scale; FOSQ: Functional Outcomes Sleep Questionnaire; NS: nonsignificant. ${ }^{\#}: p<0.001$ between baseline results and each of the follow-up visits; ": differences in the "privacy" item between baseline and follow-up visits; ${ }^{+}: p<0.05$ between the baseline visit and 1-month visit, $p<0.01$ between baseline and 3-month visit, and $p<0.001$ between baseline and 6 -month visit. *: $p<0.05$ between groups $A$ and $C$ at 1 month of follow-up. Differences were found between the baseline visit and each follow-up visit in the whole study population.

with severe OSAS (AHI $>30 \mathrm{~h}^{-1}$ ) was 13 in group $\mathrm{A}, 17$ in $\mathrm{B}$ and 15 in $\mathrm{C}$ ( $\mathrm{p}=$ nonsignificant).

Table 4 shows the compliance at each point of follow-up. At 1 month, 19 (86\%) subjects were compliant in group A, $13(59 \%)$ in B and $13(62 \%)$ in C; at 3 months $19(86 \%), 16(73 \%)$ and 14 $(67 \%)$ were compliant, respectively, and at 6 months, 16 (73\%), 15 $(68 \%)$ and $12(57 \%)$ were compliant, respectively, without significant differences between groups at each point of follow-up.

At the end of the study, $83 \%$ of patients presented good or very good tolerance for CPAP treatment. Among the adverse effects reported, dryness was the most frequent $(54 \%)$, followed by nasal congestion $(40 \%)$, leakage (26\%) and abrasions (25\%). Up to $86 \%$ of patients presented some adverse effect at some point during follow-up. Despite this, of the patients who completed the study, $91 \%$ of patients were satisfied or very satisfied with the treatment.

When analysing the questionnaire scores over the 6 months of follow-up, significant differences were seen in all the groups during the study. There was an improvement in sleepiness as measured by the ESS $(p<0.001)$, the global FOSQ score $(p<0.001)$, and the activity $(p<0.001)$ and symptom $(p<0.001)$ scores. When the scores were compared transversally, analysing the differences in scores between the three groups at each of the visits, no 


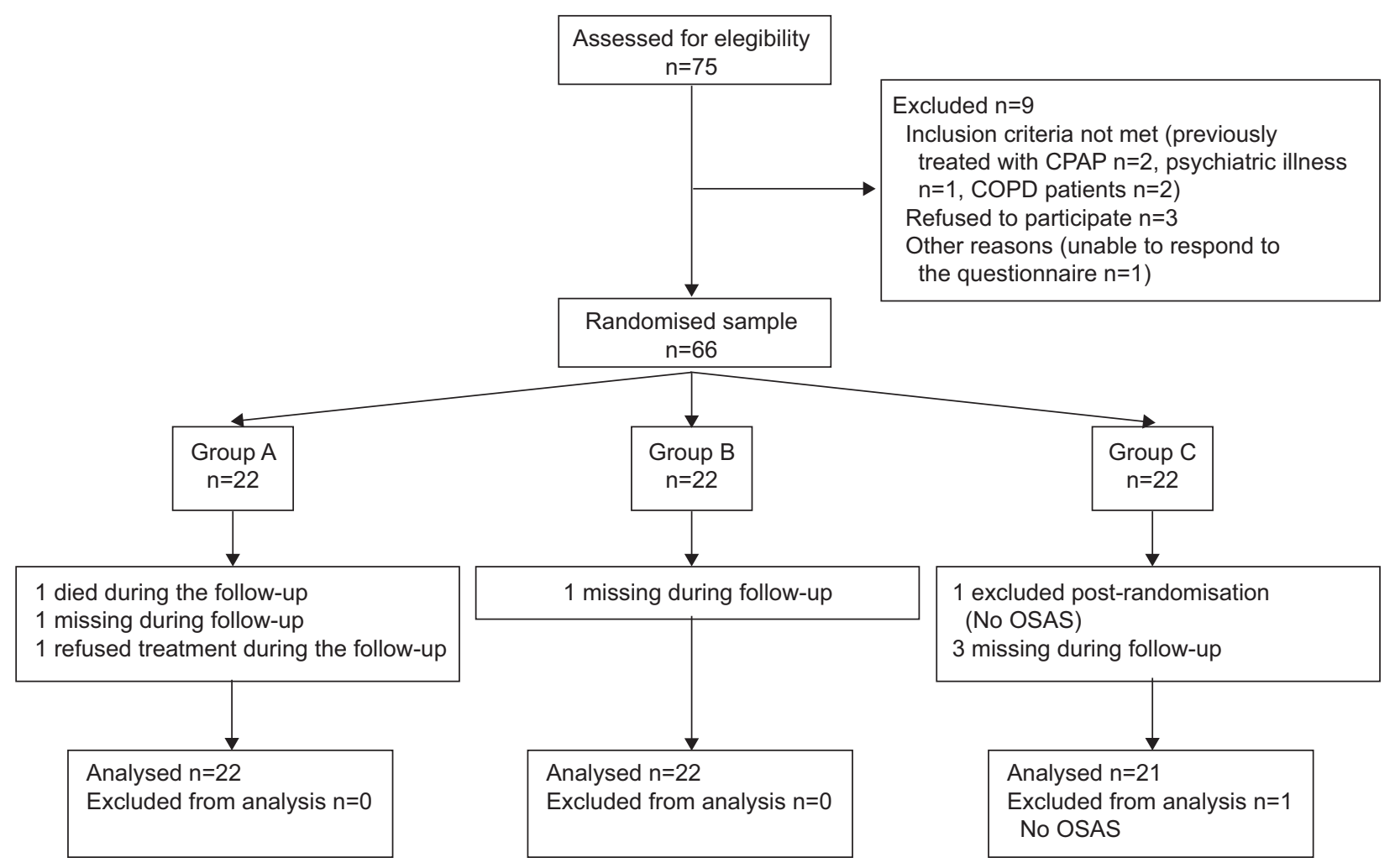

FIGURE 2. Study flow chart. CPAP: continuous positive airway pressure; COPD: chronic obstructive pulmonary disease; OSAS: obstructive sleep apnoea syndrome.

differences were found, except for the symptom questionnaire between group $\mathrm{A}$ and group $\mathrm{C}$ at 1-month follow-up, although these differences disappeared in later visits (table 2).

Five patients in group $\mathrm{A}$ and one in group $\mathrm{C}$ needed a second RP for a definitive diagnosis. One patient in group $C$ finally needed a PSG after two invalid polygraphies. Patients were contacted by phone on 24 occasions in group A. Of these, 21 were made as reinforcement during the first month of the programme, and three at the recommendation of the nurse or at the decision of the physician after studying the compliance and secondary effects records submitted. In groups B and C, contact was made 17 and 13 times, respectively. Nine patients in group A required extra visits as compared with five patients in group $\mathrm{C}$. None of the patients in group B needed extra visits (table 5).

After analysing the data on all the groups and the costs of each of the strategies, the differences in costs were statistically significant (ANOVA $p<0.001$ ), with the most expensive strategy being in group $B(€ 849 \pm 11)$, with significant differences $(p<0.001)$ from groups $A(€ 590 \pm 43)$ and $C(€ 644 \pm 93)$. The difference in costs between groups $\mathrm{A}$ and $\mathrm{C}$ was also statistically significant $(\mathrm{p}<0.05)$.

\section{DISCUSSION}

The most relevant contribution of our study is that, in patients with a high probability of OSAS, the strategy of home diagnosis and follow-up (group C) is as effective as the hospital follow-up model used in the majority of centres (groups A and B), without reducing compliance and at a lower cost. The number of cases referred for suspected OSAS and later diagnosis is very high, producing a high level of treatment demand and consequent waiting lists [12]. This study shows that an alternative home follow-up method does not affect the quality of clinical treatment and response.

The diagnosis of OSAS using a simplified methodology in the home has been shown to be valid [13-15]. Although the PSG continues to be the gold standard for diagnosis [11], unsupervised ambulatory RP is accepted in patients with a high probability of OSAS [39]. In addition, we know that the treatment response appears not to be influenced by the type of diagnostic test (PSG versus RP) [40], but the response to different follow-up strategies after the start of CPAP therapy is still unknown.

The proportion of poor CPAP compliers is variable and ranges from 30 to $50 \%$ of patients $[19,41]$. We estimated a mean $70 \%$ proportion of compliers in each arm of the study. Different methods have been used to improve compliance, such as educational sessions, telephone reinforcement, written information, video, etc., with heterogeneous results [21-24, 42]. Not all authors have been able to identify differences between intervention and nonintervention groups [43]. Still, in most cases it seems clear that some type of reinforcement can improve compliance, especially in the first few months of therapy [19].

In our study, we wanted to reinforce the role of the nurse as a fundamental pillar of the follow-up strategies. Other authors have designed programmes that include nurses in patient assessment. Hor et al. [44] randomised a group of patients diagnosed with OSAS into two groups, those with and without educational sessions, and concluded that an intensive programme by nurses could improve compliance. However, it is difficult to know whether the differences were due exclusively 
TABLE 3 Results of the diagnostic test and pressure prescribed in the initial visit

\begin{tabular}{|c|c|c|c|c|c|c|c|c|c|}
\hline Study duration min & 65 & $421 \pm 77(291-533)$ & 22 & $396 \pm 56(332-461)$ & 22 & $469 \pm 53(410-533)$ & 21 & $396 \pm 93\left(291-485^{\#}\right)$ & $0.03^{\circ}$ \\
\hline ODI $h^{-1}$ & 64 & $44 \pm 26(10-82)$ & 22 & $38 \pm 25(10-69)$ & 21 & $39 \pm 27(11-75)$ & 21 & $52 \pm 26(12-82)$ & NS \\
\hline CPAP $\mathrm{cmH}_{2} \mathrm{O}$ & 65 & $8.1 \pm 1.6(5-13)$ & 22 & $7.6 \pm 1.5(5-11)$ & 22 & $8.1 \pm 1.7(5-12)$ & 21 & $8.7 \pm 1.6(6-13)$ & NS \\
\hline
\end{tabular}

Data are presented as $n$ or mean \pm SD (range), unless otherwise stated. AHI: apnoea/hypopnoea index; ODI: oxygen desaturation index; CPAP: continuous positive airway pressure; NS: nonsignificant. ${ }^{\#}: p=0.03$, and $p<0.05$ between $B$ and $C$; $: p<0.05$ between $A$ and $B$.

to the nurses' participation or to the set of additional measures used. TOMLINSON and GIBSON [45] studied 150 patients that had started CPAP treatment and were referred to a hospital nurse for follow-up. The authors concluded that a follow-up programme by nursing is cost-effective, but the study was not controlled and their nursing team did not attend home visits. DAMJANOVIC et al. [46] randomised 100 patients into four groups formed according to the type of assessment used (standard or intensive support). The intensive support group presented a significantly greater number of hours and days of CPAP use than the standard group.

Some other authors were unable to find significant differences between interventions in these types of programmes [47]. It is possible that, in the future, new technologies such as telemedicine will have a key role in these programmes [48, 49], contributing to an increase in adherence [50]. In this regard, other recent studies have shown similar results to those presented in this work, supporting the validity of our approach $[25,51,52]$.

Our strategy is comparable to regular hospital assessment, with the advantage of reducing provider congestion, making full and rapid treatment of patients with adherence problems or side-effects possible, and to redirect time and resources to patients with specific needs. In addition, nurse visits and memory cards allow a better understanding of patterns of
CPAP use. With regard to patients, the positive reinforcement and reduced travel inherent in having nurses make home visits, as well as the possibility of being treated by the supervising physician either over the telephone or in the hospital, make adherence and compliance in the home-monitoring group favourable, with values greater even than those obtained with the conventional approach, and at a lower cost. In this sense, nurses play a key role, but the current nursing shortage fuels the search for professionals who can deliver and coordinate care effectively, and community health workers could play a role as an alternate to nurses [53].

There are some potential limitations in our study. Patients were randomised based on clinical suspicion, before confirmation by diagnostic testing. Although all but one case were confirmed, this strategy would be difficult to use in patients with an intermediate risk of illness. Nevertheless, it is estimated that $80 \%$ of patients with OSAS remain undiagnosed and there is a high percentage of severely ill patients in that group that could benefit from this strategy. Moreover, home diagnosis may lead to a large enough number of invalid tests that one of the arms of the study becomes more expensive, which is why personnel training and selection and validation of the best polygraphs are very important. In this sense, the number of invalid studies in our work was consistent with rates reported in the literature and the polygraph was previously validated. Geographical access may also be a barrier,

\section{TABLE 4 Compliance with continuous positive airway pressure (CPAP) treatment}

\begin{tabular}{|c|c|c|c|c|c|c|c|c|c|}
\hline \multirow[t]{2}{*}{ Follow-up } & \multicolumn{8}{|c|}{ Hourly counter min } & \multirow[t]{2}{*}{$p$-value } \\
\hline & & patients & & roup $A$ & & roup B & & oup C & \\
\hline 1 month min & 65 & $268 \pm 118$ & 22 & $300 \pm 85$ & 22 & $256 \pm 152$ & 21 & $240 \pm 109$ & \\
\hline Compliant & 45 & $307 \pm 83^{\star \star \star}$ & 19 & $312 \pm 69^{\#}$ & 13 & $333 \pm 95^{\star \star \star}$ & 13 & $274 \pm 85^{\#}$ & \\
\hline Noncompliant & 20 & $72 \pm 54$ & 3 & $78 \pm 52$ & 9 & $57 \pm 42$ & 8 & $95 \pm 82$ & NS \\
\hline Noncompliant & 16 & $112 \pm 55$ & 3 & $151 \pm 13$ & 6 & $103 \pm 75$ & 7 & $95 \pm 39$ & NS \\
\hline 6 months $\min$ & 65 & $262 \pm 109$ & 22 & $271 \pm 130$ & 22 & $252 \pm 100$ & 21 & $263 \pm 112$ & \\
\hline Compliant & 43 & $308 \pm 88^{\star \star \star}$ & 16 & $326 \pm 85^{\star \star \star}$ & 15 & $282 \pm 90^{\circ}$ & 12 & $315 \pm 89^{\#}$ & \\
\hline Noncompliant & 22 & $122 \pm 49$ & 6 & $93 \pm 71$ & 7 & $139 \pm 17$ & 9 & $138 \pm 27$ & NS \\
\hline
\end{tabular}

Data are presented as $n$ or mean \pm SD, unless otherwise stated. NS: nonsignificant. The differences in time of CPAP use were statistically significant in all groups and at all follow-up points, with the following levels of significance: ${ }^{* *}$ : $p<0.001,{ }^{*}: p<0.005,{ }^{\natural}: p=0.006$ 


\begin{tabular}{|c|c|c|c|c|}
\hline \multirow[t]{3}{*}{ TABLE 5} & \multicolumn{4}{|c|}{$\begin{array}{l}\text { Summary of tests, visits and extra calls by group } \\
\text { and cost }\end{array}$} \\
\hline & & \multicolumn{3}{|c|}{ Fixed costs $€$} \\
\hline & & Group A & Group B & Group C \\
\hline $\begin{array}{l}\text { Initial visit, } \\
\text { follow-up } \\
\text { diagnostic }\end{array}$ & & 3828 & 10230 & 4977 \\
\hline $\begin{array}{l}\text { Daily CPAP } \\
\text { cost }\end{array}$ & & 8237 & 8237 & 7862 \\
\hline \multicolumn{5}{|c|}{ Additional costs } \\
\hline $\mathrm{RP}$ & & 5 & 0 & 1 \\
\hline PSG & & 0 & 0 & 1 \\
\hline Extra visits & & 9 & 0 & 5 \\
\hline Extra calls & & 24 & 17 & 13 \\
\hline \multicolumn{5}{|c|}{$\begin{array}{l}\text { Total sum of } \\
\text { costs fixed } \\
\text { plus additional } €\end{array}$} \\
\hline Fixed & & 3828 & 10230 & 4977 \\
\hline Additional & & 918 & 204 & 666 \\
\hline CPAP & & 8237 & 8237 & 7862 \\
\hline Total & & 12983 & 18671 & 13505 \\
\hline $\begin{array}{l}\text { Cost per } \\
\text { patient }\end{array}$ & & 590 & 849 & 644 \\
\hline
\end{tabular}

CPAP: continuous positive airway pressure; RP: respiratory polygraphy; PSG: polysomnography. All costs were calculated by the Financial Department of the San Juan de Alicante University Hospital, Alicante, Spain. Cost of each intervention was as follows: first visit, €45; follow-up or extra visits, €30; home visits, €9; PSG, €300; RP, €72; telephone calls, €12.

although telemedicine can play a key role. AHI scores in group C were slightly higher than in the other groups, even though the differences were not statistically significant and the differences in the numbers of patients with severe OSAS between groups were also not significant. Another potential limitation was that the patients started CPAP at a pressure calculated using a mathematical formula, which could have influenced compliance. However, this technique was applied to all three groups equally and so it was not considered necessary to make later changes, depending on clinical response. Moreover, when compliance was evaluated, the fact that the home group had a memory card could have led to more accuracy in readings, due to recording of both real and effective use. Nevertheless, in the mixed and hospital follow-up groups, compliance was also evaluated using accepted objective methods from more universal clinical practice (although in the future the use of a memory card will be widespread) and furthermore the differences in time of use between groups were not significant.

We conclude that a home diagnosis and follow-up programme in patients with a high probability of OSAS, using nurses coordinated with the sleep unit, is as effective as conventional assessment, and could also be more efficient.

\section{SUPPORT STATEMENT}

Grants were funded by Carburos Médica and Fundación de Neumología de la Comunidad Valenciana.

\section{CLINICAL TRIAL}

This study is registered at clinicaltrials.gov with identifier number NCT01001858.

\section{STATEMENT OF INTEREST}

None declared.

\section{REFERENCES}

1 Young T, Palta M, Dempsey J, et al. The ocurrence of sleepdisordered breathing among middle-aged adults. $N$ Engl J Med 1993; 328: 1230-1235.

2 Durán J, Esnaola S, Ramón R, et al. Obstructive sleep apnoeahypopnoea and related clinical features in a population-based sample of subjects aged 30 to 70 years. Am J Respir Crit Care Med 2001; 163: 685-689.

3 D'Ambrosio C, Bowman T, Mohsenin V. Quality of life in patients with obstructive sleep apnoea. Effect of nasal continuous positive airway pressure: a prospective study. Chest 1999; 115: 123-129.

4 Nieto FJ, Young TB, Lind BK, et al. Association of sleep-disordered breathing, sleep apnoea and hypertension in a large communitybased study. Sleep Heart Health Study. JAMA 2000; 283: 1829-1836.

5 Barbé F, Durán-Cantolla J, Capote F, et al. Long-term effect of continuous positive airway pressure in hypertensive patients with sleep apnoea. Am J Respir Crit Care Med 2010; 181: 718-726.

6 Pack AI, Gislason T. Obstructive sleep apnoea and cardiovascular disease: a perspective and future directions. Prog Cardiovasc Dis 2009; 51: 434-451.

7 Parra O, Arboix A, Bechich S, et al. Time course of sleep-related breathing disorders in first-ever stroke or transient ischemic attack. Am J Respir Crit Care Med 2000; 161: 375-380.

8 Terán-Santos J, Jiménez-Gómez A, Cordero-Guevara J, et al. The association between sleep apnoea and the risk of traffic accidents. N Engl J Med 1999; 340: 847-851.

9 Rodenstein D. Sleep apnoea: traffic and occupational accidents individual risks, socioeconomic and legal implications. Respiration 2009; 78: 241-248.

10 Marin JM, Carrizo SJ, Vicente E, et al. Long-term cardiovascular outcomes in men with obstructive sleep apnoea-hypopnoea with or without treatment with continuous positive airway pressure: an observational study. Lancet 2005; 365: 1046-1053.

11 Douglas NJ, Thomas S, Jan MA. Clinical value of polysomnography. Lancet 1992; 339: 347-350.

12 Masa Jimenez JF, Barbé Illa F, Capote Gil F, et al. Resources and delays in the diagnosis of sleep apnoea-hypopnoea syndrome. Arch Bronconeumol 2007; 43: 188-198.

13 Chiner E, Signes-Costa J, Arriero JM, et al. Nocturnal oximetry for the diagnosis of the sleep apnoea hypopnoea syndrome: a method to reduce the number of polysomnographies? Thorax 1999; 54: 968-971.

14 Lloberes P, Sampol G, Levy G, et al. Influence of setting on unattended respiratory monitoring in the sleep apnoea/hypopnoea syndrome. Eur Respir J 2001; 18: 530-534.

15 Parra O, García-Esclasans N, Montserrat JM, et al. Should patients with sleep apnoea/hypopnoea syndrome be diagnosed and managed on the basis of home sleep studies? Eur Respir J 1997; 10: $1720-1724$.

16 Mulgrew AT, Fox N, Ayas NT, et al. Diagnosis and initial management of obstructive sleep apnoea without polysomnography. Ann Intern Med 2007; 146: 157-166.

17 Engleman HM, Kingshott RN, Wraith PK, et al. Randomised placebo-controlled crossover trial of continuous positive airway pressure for mild sleep apnoea/hypopnoea syndrome. Am J Respir Crit Care Med 1999; 159: 461-467.

18 Ballester E, Badia JR, Hernández L, et al. Evidence of the effectiviness of continuous positive airway pressure in the 
treatment of sleep apnoea/hypopnoea syndrome. Am J Respir Crit Care Med 1999; 159: 495-501.

19 McArdle N, Devereux G, Heidarnejad H, et al. Long-term use of CPAP therapy for sleep apnoea/hypopnea syndrome. Am J Respir Crit Care Med 1999; 1108-1114.

20 Weaver TE, Grunstein RR. Adherence to continuous positive airway pressure therapy: the challenge to effective treatment. Proc Am Thorac Soc 2008; 5: 173-178.

21 Fletcher EC, Luckett RA. The effect of positive reinforcement on hourly compliance in nasal continuous positive airway pressure users with obstructive sleep apnoea. Am Rev Respir Dis 1991; 143: 936-941.

22 Likar LL, Panciera TM, Erickson AD, et al. Group education sessions and compliance with nasal CPAP therapy. Chest 1997; 111: 1273-1277.

23 Richards D, Bartlett DJ, Wong K, et al. Increased adherence to CPAP with a group cognitive behavioral treatment intervention: a randomizad trial. Sleep 2007; 30: 635-640.

24 Wiese HJ, Boethel C, Philllips B, et al. CPAP compliance: video education may help!. Sleep Medicine 2005; 6: 171-174.

25 Antic NA, Buchan C, Esterman A, et al. A randomized controlled trial of nurse-led care for symptomatic moderate-severe obstructive sleep apnoea. Am J Respir Crit Care Med 2009; 179: 501-508.

26 Martinez-García MA, Soler-Cataluña JJ, Román-Sánchez $\mathrm{P}$, et al. Efficacy of a training program on sleep apnoea-hypopnoea syndrome aimed at primary care physicians. Arch Bronconeumol 2008; 44: 15-21.

27 Flemons WW, Whitelaw WA, Brant R, et al. Likelihood ratios for a sleep apnoea clinical prediction rule. Am J Respir Crit Care Med 1994; 150: 1279-1285.

28 Grupo Español de Sueño (GES). Consenso Nacional sobre el síndrome de apnoeas-hipopneas del sueño. [Spanish Group of Sleep (GES). National Consensus on sleep apnoea-hypopnoea syndrome]. Arch Bronconeumol 2005; 41: 51-67.

29 Chiner E, Signes-Costa J, Arriero JM, et al. Validation of a portable sleep monitoring device (STARDUST $\mathbb{E}$ ) for home studies. Am J Respir Crit Care Med 2003; 167: A403.

30 Andreu AL, Chiner E, Signes-Costa J, et al. Validez diagnóstica y reproductibilidad de la poligrafía respiratoria practicada en el hospital y en el domicilio [Diagnostic validity and reproducibility of respiratory polygraphy performed in the hospital and at home]. Arch Bronconeumol 2004; 40: 60.

31 Chiner E, Arriero JM, Signes-Costa J, et al. Validación de la versión española del test de somnolencia Epworth en pacientes con síndrome de apnoea de sueño [Validation of the Spanish version of the Epworth Sleepiness Scale in patients with a sleep apnea syndrome]. Arch Bronconeumol 1999; 35: 422-427.

32 Ferrer M, Vilagut G, Monasterio C, et al. Medida del impacto de los trastornos del sueño: las versiones españolas del cuestionario del impacto funcional del sueño y de la escala de somnolencia de Epworth [Measurement of the perceived impact of sleep problems: the Spanish version of the functional outcomes sleep questionnaire and the Epworth sleepiness scale]. Med Clin (Barc) 1999; 113: 250-255.

33 Weaver TE, Laizner AM, Evans LK, et al. An instrument to measure functional status outcomes for disorders of excessive sleepiness. Sleep 1997; 20: 835-843.

34 Miljeteig $\mathrm{H}$, Hoffstein $\mathrm{V}$ Determinants of continuous positive airway pressure level for treatment of obstructive sleep apnoea, Am Rev Respir Dis 1993; 147: 1526-1530.
35 Masa JF, Jiménez A, Durán J, et al. Alternative methods of titrating continuous positive airway pressure: a large multicenter study. Am J Respir Crit Care Med 2004; 170: 1218-1224.

36 Pépin JL, Krieger J, Rodenstein D, et al. Effective compliance during the first 3 months of continuous positive airway pressure. A European prospective study of 121 patients. Am J Respir Crit Care Med 1999; 160: 1124-1129.

37 Chiner E.Approach to the cost of polysomnography in a Spanish hospital. Internet J Pulmon Med 2002; 2.

38 Ministerio de Sanidad y Consumo. Real Decreto 1030/2006, por el que se establece la cartera de servicios comunes del Sistema Nacional de Salud y el procedimiento para su actualización. [Royal Decree $1030 / 2006$, on the establishing common service portfolio of the System National Health and the procedure for its actualization]. Boletín Oficial del Estado, no. 222, September 16, 2006.

39 Collop NA, Anderson WM, Boehlecke B, et al. Clinical guidelines for the use of unattended portable monitors in the diagnosis of obstructive sleep apnoea in adult patients. Portable Monitoring Task Force of the American Academy of Sleep Medicine. J Clin Sleep Med 2007; 3: 737-747.

40 Whitelaw WA, Brant RF, Flemons WW. Clinical usefulness of home oximetry compared with polysomnography for assessment of sleep apnoea. Am J Respir Crit Care Med 2005; 171: 188-193.

41 Kribbs NB, Pack AI, Kline LR, et al. Objective measurement of patterns of nasal CPAP use by patients with obstructive sleep apnoea. Am Rev Respir Dis 1993; 147: 887-895.

42 Meurice JC, Ingrand P, Portier F, et al. A multicentric trial of education strategies at CPAP induction en the treatment of severe sleep apnoea/hypopnoea syndrome. Sleep Med 2007; 8: 37-42.

43 Chervin RD, Theut S, Bassetti C, et al. Compliance with nasal CPAP can be improved by simple interventions. Sleep 1997; 20: 284-289.

44 Hoy CJ, Vennelle M, Kingshott RN, et al. Can intensive support improve continuous positive airway pressure use in patients with the sleep apnoea/hypopnoea syndrome? Am J Respir Crit Care Med 1999; 159: 1096-1100.

45 Tomlinson M, Gibson GJ. Obstructive sleep apnoea syndrome: a nurse-led domiciliary service. J Adv Nurs 2006; 55: 391-397.

46 Damjanovic D, Fluck A, Bremer $\mathrm{H}$, et al. Compliance in sleep apnoea therapy: influence of home care support and pressure mode. Eur Respir J 2009; 33: 804-811.

47 Hui DS, Chan JK, Choy DK, et al. Effects of augmented continuous positive airway pressure education and support on compliance and outcome in a Chinese population. Chest 2000; 117: 1410-1416.

48 Taylor Y, Eliasson A, Andrada T, et al. The role of telemedicine in CPAP compliance for patients with obstructive sleep apnoea syndrome. Sleep Breath 2006; 10: 132-138.

49 Stepnowsky C, Palau J, Marler MR, et al. Pilot randomized trial of the effect of wireless telemonitoring on compliance and treatment efficacy in obstructive sleep apnoea. J Med Internet Res 2007; 9: e14.

50 Smith CE, Dauz ER, Clements F, et al. Telehealth services to improve nonadherence: a placebo controlled study. Telemed $J E$ Health 2006; 12: 289-296.

51 Skomro RP, Gjevre J, Reid J, et al. Outcomes of home-based diagnosis and treatment of obstructive sleep apnoea. Chest 2010; 138: $257-263$.

52 Lettieri CF, Lettieri CJ, Carter K. Does home sleep testing impair continuous positive airway pressure adherence in patients with obstructive sleep apnoea? Chest 2011; 139: 849-854.

53 Buchan J, Aiken L. Solving nursing shortages: a common priority. J Clin Nurs 2008; 17: 3262-3268. 